\title{
Oral Mucocele of Unusual Size on the Buccal Mucosa: Clinical Presentation and Surgical Approach
}

\author{
Juliana Seo*, Ingrid Bruno, Gabriela Artico, Aluana dal Vechio and Dante A. Migliari
}

Department of Oral Medicine and Oral Pathology, School of Dentistry, University of São Paulo, São Paulo, Brazil

\begin{abstract}
Oral mucoceles are small-size, benign minor salivary gland pathologies. The most frequent localizations of these lesions are the lower lip mucosa. However, in some cases, they grow to an unusual size and hinder the preliminary diagnosis of mucocele. The purpose of this article is to report a case of a large oral mucocele with a diameter of $3.5 \mathrm{~cm}$ on the buccal mucosa of a 43-years-old male patient. The surgical procedure was carried out for a complete removal of the lesion.
\end{abstract}

Keywords: Oral mucocele, buccal mucosa, minor salivary gland.

\section{INTRODUCTION}

Oral mucoceles (OMs) are common lesions of the oral mucosa, very often arising from the rupture of a minor salivary gland duct with subsequent extravasations of mucus into surrounding soft tissue. [1]. Clinically OMs are seen as a soft, painless, translucent bluish swelling occurring most frequently on the lower labial mucosa [1,2]. Usually, they are small-sized lesions, with a mean diameter of less than 1 $\mathrm{cm}[1]$.

This article reports a case of a large OM resembling a begin neoplasm, located on the buccal mucosa.

\section{CASE REPORT}

A 43-year-old male patient sought our clinic complaining of a rather large, painless swelling on the left buccal mucosa, which had been present for 1 year. Intraoral examination showed a bluish nodule, of approximately $3.5 \mathrm{~cm}$ in diameter, covered by a normal mucosa (Fig. 1a). On palpation, the lesion was soft and painless. His oral hygiene was satisfactory, though he had lost teeth 34 and 35 . The patient had no history of trauma to the affected area. The cervical lymph nodes were not palpable. His medical records revealed hypertension controlled with antihypertensive drugs.

The overall clinical appearance of the lesion suggested a benign lesion. The differential diagnoses included a large mucocele, pleomorphic adenoma and lipoma. The latter was excluded from the diagnosis based on the lesion's bluish color, and pleomorphic adenoma was also excluded because of the softness and spongy texture and the cyst-like nature (Fig. 1b). Therefore, a surgical excision was carried out under local anesthesia with a 1-cm-wide fusiform incision made over the lesion, followed by a gentle dissection to avoid any tissue rupture and the recovery was uneventful.

*Address correspondence to this author at the Disciplina de Estomatologia Clínica Faculdade de Odontologia, Universidade de São Paulo Av. Prof. Lineu Prestes, 2227, Cidade Universitária São Paulo, SP - Brazil 05508900; Tel/Fax: (+55 11 3091-7883); E-mail: juliana.seo@usp.br
(Fig. 1c and d). Microscopic examination showed a central area of amor phous mucous-like material surrounded by a granulation tissue containing foamy macrophages. Adjacent minor salivary glands, dilated ducts and fragments of mucosa covered by stratified squamous epithelium could be also observed. The histopathological analysis confirmed the diagnosis of mucocele (Fig. 1e). After a 12-month follow-up there was total healing without recurrence (Fig. 1f).

\section{DISCUSSION}

OMs are asymptomatic lesions in most cases, but, in a few instances, when appearing as multiple and recurrent lesions they may cause severe pain. The lower lip is the most common site, although they can be found in any region where there are salivary glands, but rarely in the palate, retromolar space and the buccal mucosa [1-3]. The present case was uncommon in light of the lesion's diameter (3.5 $\mathrm{cm}$ ), which was well-above the average size reported in the literature (usually around $1 \mathrm{~cm}$ ) and its location on the buccal mucosa.

Treatments for OMs include cryotherapy, carbon dioxide and erbium lasers, intralesional corticosteroid, and topical gamma-linolenic acid; however the gold standard treatment is surgical excision [4]. Surgical excision was chosen in this case, because it allowed for a complete removal of the lesion as well as its histopathological examination. Moreover, this method avoids recurrences [5].

The classic characteristics for the differential diagnosis of $\mathrm{OM}$ are a history of trauma and the rapid appearance of a bluish swelling generally on the lower lip mucosa $[1,2,5]$. However, our patient had no history of trauma associated to the development of the lesion. In this respect, it is possible to speculate that the absence of premolar teeth may have led to a repeated trauma by the patient's involuntarily sucking his buccal mucosa, thus causing the development of this large OM. In order to minimize relapses it is important to remove the lesion completely and provide the patient with a dental prosthesis to prevent tooth displacements and development 




Fig. (1). Clinical, surgical and histopathological aspects of mucocele. (a) A large bluish nodule on the buccal mucosa; (b) Depressability of the lesion on palpation; (c) Dissection showing the translucent aspect of the lesion; (d) Macroscopic aspect of the lesion following its complete excision; (e) Histological section presenting mucosal epithelium and granulation tissue surrounded spilled mucin and foamy macrophages (haematoxylin and eosin stain, 100x); (f) Twelve months follow-up showing complete healing and absence of fibrosis.

of dysfunctional habits. Our patient has forgone the prosthetic treatment, but, so far, no recurrence has been observed.

\section{REFERENCES}

[1] Chi AC, Lambert PR 3rd, Richardson MS, Neville BW. Oral Mucoceles: a clinicopathologic review of 1,824 cases, including unusual variants. J Oral Maxillofac Surg 2011; 69(4):1086-93.
[3] Re-Cecconi D, Achilli A, Tarozzi M, et al. Mucoceles of the oral cavity: a large case series (1994-2008) and a literature review. Med Oral Patol Oral Cir Bucal 2010; 15(4): 551-6.

[4] Luiz AC, Hiraki KR, Lemos CA Jr, Hirota SK, Migliari DA. Treatment of painful and recurrent oral mucoceles with a highpotency topical corticosteroid: a case report. J Oral Maxillofac Surg 2008; 66(8): 1737-9.

[5] Tran TA, Parlette HL 3rd. Surgical pearl: removal of a large labial mucocele. J Am Acad Dermatol 1999; 40(5 Pt 1): 760-2.

Received: January 09, 2012

(C) Seo et al.; Licensee Bentham Open.

This is an open access article licensed under the terms of the Creative Commons Attribution Non-Commercial License (http://creativecommons.org/licenses/by-nc/3.0/) which permits unrestricted, non-commercial use, distribution and reproduction in any medium, provided the work is properly cited. 